\title{
The advantages and disadvantages of using High Fidelity Simulation as an environment to observe undergraduate nurses' actions and their alignment with clinical judgement characteristics
}

\author{
Sharon Jacobs*, Christine Taylor, Kathleen Dixon, Lesley Wilkes \\ Western Sydney University, Australia
}

Received: September 16, 2019

Accepted: November 18, 2019

Online Published: November 25, 2019

DOI: $10.5430 / \mathrm{cns} . v 8 \mathrm{n} 1 \mathrm{p} 15$

URL: https://doi.org/10.5430/cns.v8n1p15

\begin{abstract}
Background: High Fidelity Simulation (HFS) is used as an environment for research and education into clinical judgement in nursing with positive results. Nursing actions are important aspects of clinical judgement. Observing nursing actions could provide an opportunity to identify the characteristics of clinical judgement. Therefore, the environment of HFS was chosen for this research as an observational tool.

Aim: The aim of this paper is to discuss the advantages and disadvantages of using HFS as an environment for the research in aligning the nursing actions of undergraduate nurses to characteristics of clinical judgement.

Methods: The study discussed in this paper was conducted in a simulation laboratory housing an HFS manikin within a large Australian university. The study used a descriptive research design with 18 undergraduate nurses agreeing to participate.

Results: The major advantage of using HFS was that it provided a real time and safe platform to determine the nursing actions enacted which represented the characteristics of clinical judgement. The major disadvantage in our research was that only one person was available to conduct the research. It is also time consuming to both create an authentic scenario as well as preparation prior to conducting a simulation session.

Conclusions: HFS provided an ideal environment to observe the actions of undergraduate student nurses and aligning these actions to the characteristics of clinical judgement.

Implications: In using HFS for research the availability of participants needs to be negotiated. Individual rather than group assessment will provide clearer identification of needs of students to be developed.
\end{abstract}

Key Words: High Fidelity Simulation, Undergraduate nurses, Characteristics of clinical judgement, Nursing actions

\section{INTRODUCTION}

Failure to identify fluctuations in the patient's condition remains a problem within the healthcare sector. ${ }^{[1]}$ While the reasons are complex and overlapping, a nurse's clinical judgement is accepted in the literature as being an important com- ponent in identifying these early fluctuations in the patient's condition. ${ }^{[2,3]}$ Clinical judgement is extensively critiqued in the literature and nurses have been found to not always display appropriate clinical judgement in practice. ${ }^{[4-8]}$

Clinical judgement in nursing is defined as the gathering of

*Correspondence: Sharon Jacobs; Email: s.jacobs@westernsydney.edu.au; Address: Western Sydney University, Australia. 
patient details, the interpretation of these, making an assumption related to the details collected, responding by nursing actions and reflecting on and evaluating the patient's responses to these actions. ${ }^{[9-12]}$ Therefore, nursing actions are considered to be an important component of making a clinical judgement. The resultant nursing actions are also dependent on the expertise of the individual's clinical judgement. ${ }^{[13]}$

The characteristics of clinical judgement have been described by several authors such as Standing, ${ }^{[14]}$ Tanner, ${ }^{[15]}$ Lasater $^{[11]}$ and Alfaro-LeFevre. ${ }^{[16]}$ Jacobs, Wilkes ${ }^{[17]}$ reviewed definitions of clinical judgement and identified the following 12 common characteristics: "context dependent", "theoretical knowledge", experiential knowledge", "practical knowledge", "collection of data/Interpretation of patient's needs/prioritizing data", "culminates in a clinical decision", "essential for safe patient/client care", "systematic process", "pattern recognition and synthesis", "reflective", "evaluation of choices made" and "culminates in a management plan". Nursing actions are an integral component of clinical judgement, yet there is a lack of research relating specific nursing actions to characteristics. The aim of this paper is to discuss the advantages and disadvantages of using HFS as an environment for the research in aligning the nursing actions of undergraduate nurses to characteristics of clinical judgement.

\section{MeTHODS}

Our research utilised a descriptive research design which involved observation of nursing actions individual undergraduate nurses take when caring for a patient experiencing respiratory difficulties. The participants were student nurses early in the semester of their second or third semester of a six-semester undergraduate nursing program. Eighteen undergraduate nurses agreed to participate in the research.

The research setting was a large nursing school within a multi campus Australian University which has a diverse student cohort. Research data was collected in a nursing laboratory across three campuses within a designated simulation area. This area consists of two rooms one of which houses a highfidelity manikin (Laerdal ${ }^{\circledR}$ SimMan) designed to mirror a single room environment in the clinical setting. The adjoining room contain the controls to operate the manikin and provided an area to observe the actions of the participants via a window.

All participants had successfully completed a basic anatomy and physiology subject six months after commencement of their nursing program. All the participants as part of their program had been educated to obtain vital signs, and the initial assessment of a patient experiencing respiratory difficulties using simulation. While simulation had been utilised in the clinical laboratories this was mainly restricted to low fidelity simulation and therefore the participants had not been exposed to high-fidelity simulation. Participants had not been educated in the pathophysiology related to respiratory disorders prior to the simulation session.

The research used a HFS scenario of a patient experiencing respiratory distress which provided an opportunity for researchers to observe the actions the participants took that characterise clinical judgement. A patient with COPD was chosen as these patients often experience significant exacerbation of respiratory distress. The aim of the scenario session was for participants to perform a preliminary respiratory assessment according to the $\mathrm{ABC}$ algorithm. ${ }^{[18]}$

During the participants pre-briefing session (before the simulation activity), a multiple-choice questionnaire was administered to determine participants level of theoretical knowledge related to respiratory distress. The questionnaire was administered as knowledge is considered a characteristic of clinical judgement ${ }^{[15,19]}$ and in the definition used in this research. ${ }^{[17]}$ Nursing actions of the participants were observed during the HFS activity. Following the debriefing session, alignment to the characteristics of clinical judgement was conducted using a checklist (see Table 1).

\subsection{Ethics}

Before the collection of data approval from the University's Human Research Ethics Committee was obtained. The research complied with the Australian National Health and Medical Research Council [NHRMC, 2018] guidelines for ethical conduct of research.

\section{THE USE OF HFS}

Simulation is the creation of an event, situation or environment that replicates what participants encounter in the clinical setting. ${ }^{[20-22]}$ High Fidelity Simulation is a technique which utilises a manikin to mimic characteristics of humans. The manikin has programmable software, with the capacity to replicate physiological parameters (such as breathing) and can be programmed to respond to nursing actions without a delay. ${ }^{[23]}$ The focus for this research was the observable nursing actions performed by participants responding to the patients' needs that reflected the characteristics of clinical judgement.

There are three phases to HFS that provide a robust and effective simulation experience, and can engage the participants on an emotional, cognitive and psychomotor level. ${ }^{[24]}$ The initial phase consists of a pre-briefing/briefing session which introduces and provides an outline of what is expected from participants during the scenario is presented. The major 
purpose of this phase is to prepare participants, enhance participation, facilitates effectiveness of the simulation session and reduce participant anxiety. ${ }^{[25-27]}$ In order to provide the context for the research participants were provided with a set of patient notes which included the current status of the patient, patient history, nursing report and relevant patient charts such as observation and medication charts.

Objectives for the HFS session were provided to the participants, based on the initial assessment of the patient expe- riencing respiratory difficulties, gathering of patient details and the response of the participants to the data collected. The participants were given time to orientate themselves to the environment and the equipment and were instructed to indicate to the researcher when they were ready to start the session. During the "pre-briefing session" a multiple-choice questionnaire (MCQ) was administered to establish participants' theoretical knowledge (a characteristic of clinical judgement) related to a patient experiencing respiratory distress.

Table 1. The phases of HFS and the alignment of nursing actions to characteristics of clinical judgement

\begin{tabular}{|c|c|c|}
\hline Stages of HFS & Characteristic of CJ & Nursing action completed by the participants \\
\hline Pre-brief & $\begin{array}{l}\text { - Context } \\
\text { - Knowledge (Theory, Experiential, Practice) }\end{array}$ & $\begin{array}{l}\text { Reading of patient notes and relevant paperwork } \\
\text { Completion of MCQ }\end{array}$ \\
\hline Simulation session & $\begin{array}{l}\text { - Observation of actions } \\
\text { - Collection of data/Interpretation of patient's } \\
\text { needs/prioritizing data } \\
\text { - Culminates in a clinical decision } \\
\text { - Safe patient/client care } \\
\text { - Systematic process } \\
\text { - Pattern recognition } \\
\text { - Reflection-in-action }\end{array}$ & $\begin{array}{l}\text { Observation of the following: } \\
\text { - Did participants follow the ABC algorithm by } \\
\text { - Checking airway } \\
\text { - Breathing } \\
\text { - Circulation } \\
\text { Obtaining vital signs - oxygen saturation, measurement of BP } \\
\text { Respiratory rate - depth and rate of breathing, patient's colour } \\
\text { Also, observation for outcomes: } \\
\text { - Did the participants respond to the patient's initial statement of } \\
\text { having difficulty breathing? } \\
\quad \text { Positioning patient } \\
\text { - Administering oxygen } \\
\text { then increasing oxygen flow rate when saturations remained } \\
\text { low }\end{array}$ \\
\hline Debriefing & $\begin{array}{l}\text { Reflection } \\
\text { - Evaluation of choices made } \\
\text { - Culminates in a management plan } \\
\text { - Systematic process } \\
\text { - Pattern recognition \& synthesis }\end{array}$ & $\begin{array}{l}\text { - Post interview debriefing } \\
\text { - Discussion of the use of ABC algorithm } \\
\text { - Were they able to identify patterns in the patients' presentation } \\
\text { - Were they able to identify a nursing management plan for the } \\
\text { patient } \\
\text { - Did they follow a systematic process? } \\
\text { - Reflection-on-action - demonstrated during the interviews }\end{array}$ \\
\hline
\end{tabular}

The MCQ test revealed that participants were able to recognise abnormal signs and symptoms but did not select the most appropriate responses to questions relating to evaluation of care given or linking the underlying pathophysiology to the signs and symptoms. These responses were to be expected, as students had not been exposed to theory relating to a specific respiratory condition before the MCQ tests.

The second phase "the simulation activity" was guided by the ABC (Airway, Breathing, Circulation) algorithm which is the international standard of care for patients' experiencing respiratory difficulties and is widely utilized. ${ }^{[18]}$ Participants' nursing action following their initial assessment using the
$\mathrm{ABC}$ algorithm were observed and recorded using a checklist to identify if any characteristics of clinical judgement were missing (see Table 1). The software associated with the Laerdal ${ }^{\circledR}$ SimMan also produced a log of when actions were being performed which assisted the observer to sequence their actions.

The third phase, "the debriefing session", is emphasised in the literature as an important component of simulation-based training. ${ }^{[28-31]}$ The focus of debriefing is aligning the objectives of the session and the of expected goals to determine if the aims for the simulation have been met. ${ }^{[32]}$ During the debriefing session participants' nursing actions and the char- 
acteristics of clinical judgement (see Table 1) were explored and analysed. Characteristics included participants evaluating the nursing actions they made, discussing the data they collected, reasons that guided their actions, identifying any gaps in their knowledge for further study as well as reinforcing their knowledge after the simulation session. Feedback was provided by the researcher, encouraging the participants to integrate their experiences through guided reflection using the Gibbs reflective cycle. ${ }^{[33]}$ The participants had been exposed to the Gibbs reflective cycle as it has been used extensively in their undergraduate nursing program. The Gibbs reflective tool is a cyclical process which assist participants to incorporate the experience.

\section{REFLECTIONS ON USING HFS}

Personal reflection of the researchers using HFS as the context for our research identified several advantages and disadvantages that were encountered in using this technology. These will be discussed in depth below.

\subsection{Advantages}

One of the major advantages for the use of HFS in our research was that identified characteristics of clinical judgement could be observed in the nursing actions undertaken during the three phases of HFS. As clinical judgement is difficult to observe and measure the identification of the characteristics will make it easier to describe and ultimately observe. It is important to identify nursing actions that relate specifically to the characteristics of clinical judgement before coming to any conclusions associated with the development thereof.

Another advantage of using HFS in our research was that it more closely resembles real life situations with the use of the programmed manikin allowing a real time-response from the participant in a replicated clinical environment. The scenario also added to the realism as it was developed by the principal researcher who was an expert respiratory intensive care nurse. The scenario related to COPD as these patients have significant episodes of respiratory distress. Using a realistic and safe environment allows participants to practise the nursing actions associated with clinical judgement without compromising the patient's safety. This enhances the ability to exercise clinical judgement in real-time in a clinical situation. HFS also allows focused and repetitive practice which is associated with improved outcomes for participants. ${ }^{[34]}$

Another advantage in using HFS is that the environment is controlled, minimising interruptions and allowing participants to concentrate on the activity. In our research the controlled setting also allowed the researcher to concentrate on observing the individual participant's clinical judgement.
While this might not be representative of the numerous demands on nurses in clinical practice our research sought to identify if the participants exhibited the characteristics of clinical judgment in relation to the clinical scenario.

A further advantage in using the Laerdal $($ SimMan is a digital $\log$ that enabled the recording of the time taken to commence and to sequence the nursing actions undertaken. The data was utilised during the debriefing session in the post simulation activity.

\subsection{Disadvantages}

From a perspective of our research HFS provided few disadvantages. In our research a major issue was recruitment as the participants' nursing school did not allow for the collection of data during normal curriculum time resulting in low participant numbers. Participants appeared reluctant to participate as it was not timetabled into the nursing program. This was despite flyers promoting the research posted for two semesters in all areas that potential participants had access to. Researchers in other studies relating to the effect of HFS on clinical judgement have collected data during normal class times. ${ }^{[23,31,35,36]}$

The use of HFS is time consuming for both students and researcher. Conducting the research on individual participants was time consuming both in data collection and preparation time for each participant. Time was also spent to formulate and test the scenario prior to its use. The simulation session also needed to be structured when the equipment was available outside of class times.

HFS involves complex equipment and unexpected technical issues can interrupt participant performance and influence the reality of the scenario. For example, a disconnection between the manikin and the computer program after the scenario has commenced requires the scenario to be restarted which could impact on the participant's performance. While this did not occur in our research it has been experienced by the researcher in other simulation sessions. Also, staff expertise is required to troubleshoot any technical problems that may arise. Videoing participants have been used in other studies and has shown to be valuable, ${ }^{[37,38]}$ however this was not available for our research as technical problems related to the cameras were experienced. On reflection it would been beneficial to have two observers to verify observations.

\section{Conclusions}

The use of HFS in our research proved to be a valuable environment to observe the nursing actions related to the characteristics of clinical judgement enacted by the participants when caring for a patient experiencing respiratory 
difficulties. In developing the scenario for HFS it is important to identify the characteristics of clinical judgement and the associated actions for each of the three phases. HFS can also be used to determine if the participants' actions and the characteristics of clinical judgement improve over time.

While there are disadvantages to the use HFS as a research environment it is valuable in observing nursing actions and their alignment to the characteristics of clinical judgement. It provides a situation to assess participants' clinical judgement in a representative clinical environment without compromising patient safety. HFS is however, expensive in researcher's time both in conducting the scenario and recruiting individual participants. To use HFS as an environment for research it is important that there are at least two observers.

\section{CONFlicts of InTEREST Disclosure}

The authors declare they have no conflicts of interest.

\section{REFERENCES}

[1] Clinical Excellence Commission, Clinical Incident Management, D.o. Health, Editor. NSW Department of Health: Sydney, Australia; 2018.

[2] Douglas K. The effect of the developing nurses' thinking model on clinical judgment in nursing students, in Faculty of The Graduate School. Gardner-Webb University. 2014.

[3] Levett-Jones T, Hoffman K, Dempsey J, et al. The 'five rights' of clinical reasoning: An edeucational model to enhance nursing students' ability to identify and manage clinically 'at risk' patients. Nurse Education Today. 2010; 30: 515-520. PMid: 19948370. https://doi.org/10.1016/j.nedt.2009.10.020

[4] El Haddad M, Moxham L, Broadbent M. Graduate registered nurse practice readiness in the Australian context: An issue worthy of discussion. Collegian. 2013; 20(4): 233-238. PMid: 24596992. https://doi.org/10.1016/j.colegn.2012.09.003

[5] Candela L, Bowles C. Recent RN graduates perception of educational preparation. Nurse Education Perspectives. 2008; 29(5): 269-271.

[6] Mirza N, Manankil-Rankin L, Prentice D, et al. Practice readiness of new nursing graduates: A concept analysis. Nurse Education in Practice. 2019; 37: 68-74. PMid: 31112923. https: //doi.org/10.1016/j.nepr.2019.04.009

[7] Lindsey P, Jenkins S. Nursing students' clinical judgement regarding rapid respone: the influence of a clinical education intervention. Nursing Forum. 2013; 48(1): 61-70. PMid: 23379397. https://doi.org/10.1111/nuf.12002

[8] Nielsen A, Lasater K, Stock M. A framework to support preceptors' evaluation and development of new nurses' clinical judgment. Nurse Education in Practice. 2016; 19: 84-90. PMid: 27428698. https://doi.org/10.1016/j.nepr.2016.03.012

[9] Benner PRNPF, Tanner CARNPF, Chesla CARND. Expertise in Nursing Practice, Second Edition: Caring, Clinical Judgment, and Ethics. New York, United States: Springer Publishing Company; 2019.

[10] Phaneuf M. Clinical judgement - an essential tool in the nursing profession. 2008.

[11] Lasater K. Clinical judgement: The last frontier for evaluation. Nurse Edcuation in Practice. 2011; 11: 86-92. PMid: 21212021. https://doi.org/10.1016/j.nepr.2010.11.013

[12] Victor-Chmil J. Critical thinking versus clinical reasoning versus clinical judgement differential diagnosis. Nurse Educator. 2013; 38(1): 34-36. PMid: 23222632. https ://doi .org/10.1097/NNE. 0 b01 3e318276 df be

[13] Fedko A. Examining the relationship between clinical judgement and nursing action in Baccalaureate nursing students, in School of Nursing. Indiana University: Ann Arbor, MI; 2016. 176 p.
[14] Standing M. Clinical judgement and decision-making - in nursing nine modes of practice in a revised cognitive continuum. Journal of Advanced Nursing. 2001; 62(1): 124-134. PMid: 18352971 https://doi.org/10.1111/j.1365-2648.2007.04583.x

[15] Tanner C. Thinking like a nurse: A research-based model of clinical judgement in nursing. Journal of Nursing Education. 2006; 45(6): 204-211. PMid: 16780008 . https://doi.org/10.3928/014848 34-20060601-04

[16] Alfaro-LeFevre R. Critical thinking, clinical reasoning and clinical judgement a practical approach. St Louis: Elsevier Saunders; 2013.

[17] Jacobs S, Wilkes L, Taylor C, et al. Addressing the challenge of developing a conceptual definition for clinical judgment. Nursing and Health. 2016; 4(1): 1-8. https ://doi .org/10.13189/nh. 2016 .040101

[18] Robinson T, Scullion J. Oxford handbook of respiratory nursing. Oxford: Oxford University Press; 2009.

[19] van Graan A, Williams M, Koen M. Clinical judgement within the South African clinical nursing environment: A concept analysis. Health SA Gesondheit. 2016; 21: 33-45. https://doi.org/10.1 016/j.hsag. 2015.05.003

[20] Brooks N, Moriarty A, Welyczko N. Implementing simulated practice learning for nursing students. Nursing Standard. 2010; 24(20): 41-45. PMid: 20191744. https ://doi.org/10.7748/ns . 24.20 $.41 . \mathrm{s} 48$

[21] Cant R, Cooper S. Use of simulation-based learning in undergraduate nurse education: An umbrella systematic review. Nurse Education Today. 2017; 49: 63-71. PMid: 27902949. https ://doi .org/10 $.1016 / j$.nedt .2016 .11 .015

[22] Hallin K, Bäckström B, Häggström M, et al. High-fidelity simulation: Assessment of student nurses' team achievements of clinical judgement. Nurse Education in Practice. 2016; 19: 12-18. PMid: 27428686. https://doi.org/10.1016/j.nepr. 2016.03.010

[23] Kelly M. Investigating the use of simulations in enhancing clinical judgement of students to practice as registered nurses, in Faculty of Arts and Social Sciences. University of Technology, Sydney; 2014. $279 \mathrm{p}$.

[24] Huggins C. Three phases of simulation. n.d. Accessed 21/9/2018. Available from: www.simulationaustralasia.com/files/up load/pdf/research/31-10.pdf

[25] Chamberlain J. Prebriefing in nursing simulation: A concept analysis using Rodger's methodology. Clinical Simulation in Nursing. 2015; 11(7): 318-322. https://doi.org/10.1016/j.ecns.2015.05 .003

[26] McDermott D. The prebriefing concept: A Delphi study of CHSE experts. Clinical Simulation in Nursing. 2016; 12(6): 219-227. https://doi.org/10.1016/j.ecns.2016.02.001 
[27] Page-Cutrara K, Turk M. Impact of prebriefing on competency performance, clinical judgement and experience in simulation: An experimental study. Nurse Education Today. 2017; 48: 78-83. PMid: 27721089. https://doi.org/10.1016/j.nedt.2016.09.012

[28] Dreifuerst K. The essentials of debriefing in simulation learning: A concept analysis. Nursing Education Perspectives. 2009; 30(2): 109-114.

[29] Mariani B, Cantrell MA, Meakim C, et al. Structured debriefing and students' clinical judgement abilities in simulation. Clinical Simulation in Nursing. 2013; 9: e147-e155. https://doi.org/10.101 $6 / j$.ecns. 2011.11.009

[30] Forneris SG, Neal DO, Tiffany J, et al. Enhancing clinical reasoning through simulation debriefing: A multisite study. Nursing Education Perspectives. 2015; 36(5): 304-310. PMid: 26521499. https://doi.org/10.5480/15-1672

[31] Al Sabei S, Lasater K. Simulation debriefing for clinical judgement development: A concept analysis. Nurse Education Today. 2016; 45: 42-47. PMid: 27429402. https://doi.org/10.1016/j.nedt. 2 016.06 .008

[32] INACSL Standards Committee. INACSL standards of best practice: Simulation debriefing. Clinical Simulation in Nursing. 2016; 12: S21-S25. https://doi.org/10.1016/j.ecns.2016.09.008

[33] Gibbs G. Learning by doing: A guide to teaching and learning methods. Oxford, UK: Oxford Further Education Unit; 1998.
[34] Sawyer T, Sierocka-Castaneda A, Chan D, et al. Deliberate practice using simulation improves neonatal resuscitation performance. Simulation in Healthcare. 2011; 6(6): 327-336. PMid: 21937960 https ://doi.org/10.1097/SIH.0b013e31822b1307

[35] Ashcraft A, Opton L, Bridges RA, et al. Simulation evaluation using modified Lasater Clinical Judgement Rubric. Nursing Education Perspectives. 2013; 34(2): 122-126. PMid: 23763027. https://doi .org/10.5480/1536-5026-34.2.122

[36] Fawaz M, Hamden-Mansour A. Impact of high-fidelity simulation on the development of clinical judgement and motivation among Lebanese nursing students. Nurse Education Today. 2016; 46: 3642. PMid: 27591378. https ://doi.org/10.1016/j.nedt. 201 6.08 .026

[37] Grant J, Dawkins D, Molhook L, et al. Comparing the effectiveness of video-assisted oral debriefing and oral debriefing alone on behaviors by undergraduate nursing students during high-fidelity simulation. Nurse Education in Practice. 2014; 14: 479-484. PMid: 24929548. https://doi.org/10.1016/j.nepr.2014.05.003

[38] Herron E, Powers K, Mullen L, et al. Effect of case study versus video simulation on nursing students' satisfaction, self-confidence, and knowledge: A quasi-experimental study. Nurse Education Today. 2019; 79: 129-134. PMid: 31125766. https://doi.org/10.101 $6 / j \cdot$ nedt.2019.05.015 